\title{
Responsible leadership in global business: a new approach to leadership and its multi-level outcomes
}

\author{
Vögtlin, Christian ; Patzer, Moritz ; Scherer, Andreas Georg
}

\begin{abstract}
The article advances an understanding of responsible leadership in global business and offers an agenda for future research in this field. Our conceptualization of responsible leadership draws on deliberative practices and discursive conflict resolution, combining the macro-view of the business firm as a political actor with the micro-view of leadership. We discuss the concept in relation to existing research in leadership. Further, we propose a new model of responsible leadership that shows how such an understanding of leadership can address the challenges of globalization. We thereby propose positive outcomes of responsible leadership across levels of analysis. The model offers research opportunities for responsible leadership in global business.
\end{abstract}

DOI: https://doi.org/10.1007/s10551-011-0952-4

Posted at the Zurich Open Repository and Archive, University of Zurich

ZORA URL: https://doi.org/10.5167/uzh-54255

Journal Article

Published Version

Originally published at:

Vögtlin, Christian; Patzer, Moritz; Scherer, Andreas Georg (2012). Responsible leadership in global business: a new approach to leadership and its multi-level outcomes. Journal of Business Ethics, 105(1):116.

DOI: https://doi.org/10.1007/s10551-011-0952-4 


\title{
Responsible Leadership in Global Business: A New Approach to Leadership and Its Multi-Level Outcomes
}

\author{
Christian Voegtlin • Moritz Patzer • \\ Andreas Georg Scherer
}

Received: 17 December 2010/Accepted: 19 June 2011/Published online: 1 July 2011

(C) Springer Science+Business Media B.V. 2011

\begin{abstract}
The article advances an understanding of responsible leadership in global business and offers an agenda for future research in this field. Our conceptualization of responsible leadership draws on deliberative practices and discursive conflict resolution, combining the macro-view of the business firm as a political actor with the micro-view of leadership. We discuss the concept in relation to existing research in leadership. Further, we propose a new model of responsible leadership that shows how such an understanding of leadership can address the challenges of globalization. We thereby propose positive outcomes of responsible leadership across levels of analysis. The model offers research opportunities for responsible leadership in global business.
\end{abstract}

Keywords Business ethics - Corporate social responsibility - Globalization · Leadership ethics · Responsible leadership

\section{Introduction}

Amidst the various reports on the financial crisis, corporate scandals and managerial misconduct that have been prevalent in media headlines for over a year, a common denominator seems to be an interest in attributing the

C. Voegtlin $(\bowtie) \cdot$ M. Patzer · A. G. Scherer

Department of Business Administration (IBW), University

of Zurich, Universitätsstrasse 84, 8006 Zurich, Switzerland

e-mail: christian.voegtlin@uzh.ch

M. Patzer

e-mail: moritz.patzer@uzh.ch

A. G. Scherer

e-mail: andreas.scherer@uzh.ch failures to the challenges of global business. In a time when it has become increasingly difficult, if not impossible, to delineate systemic outcomes and individual responsibilities, ethics and morality have once again become frontpage news. As a consequence, theory and practice are struggling with the task of re-conceptualizing the role of corporations (Scherer and Palazzo 2008a, 2011) and their leaders (Doh and Stumpf 2005a; Maak and Pless 2006a; Waldman and Siegel 2008) in society, in order to address the surge of public concerns.

So far leadership ethics, as the overarching term for the inclusion of ethical aspects in leadership, has remained an underdeveloped field (Ciulla 1995, 2005; Doh and Stumpf 2005b). Only recently, leadership research once again turns its focus on the phenomenon of leadership ethics in its different facets. Thus, many new approaches within leadership connect to ethical or moral themes. Among these are the concept of ethical leadership, which tries to measure empirically what ethical leadership means (Brown 2007; Brown and Trevino 2006; Brown et al. 2005; Trevino et al. 2000, 2003); the already well-established transformational leadership concept, where more recent research (Bass and Steidlmeier 1999) tries to regain an awareness of the moral roots of its founder, James M. Burns (1978), also, e.g., by looking at the connection between corporate social responsibility (CSR) and transformational leadership (Waldman et al. 2006); authentic leadership, understood as leadership that displays leader behavior true to the inherent moral values of the leader (Avolio and Gardner 2005; Avolio et al. 2004a, b; Gardner et al. 2005; Ilies et al. 2005; Walumbwa et al. 2008); an understanding of leaders as "servants" in the conception of servant leadership (Greenleaf 1977; Liden et al. 2008), and other approaches that address the ethical or moral challenges of leaders (e.g., Fry 2005; Johnson 2009; von Weltzien Hoivik 2002). 
Though these efforts have undoubtedly made vital contributions to the field, we argue that they are limited due to conceptual constraints, because they do not adequately encompass the causes and implications of present leadership challenges. As we outline below, we see these challenges rooted in the economic and moral implications of globalization (Scherer and Palazzo 2008b, 2011). An appropriately extended understanding of leadership has to take these into account with regard to the individual's actions as well as their organizational and societal embeddedness. The inclusion of the latter poses a significant research gap, since present leadership theory remains primarily focused on the micro level perspective of internal organizational behavior (House and Aditya 1997, pp. 445f; Osborn et al. 2002; Waldman et al. 2006, p. 1705). Yet, it is our understanding that only by bridging the organizational level of corporate responsibility and the individual level of leadership responsibility does one do justice to the pluralistic and multifaceted tasks present leaders have to attend to (see also Bies et al. 2007; Doh and Stumpf 2005b; Palazzo and Scherer 2008, pp. 583f; Waldman et al. 2006; Waldman and Siegel 2008, p. 117). Furthermore, leadership ethics can benefit from the discussions on the responsibility of the firm with concepts like CSR, Corporate Citizenship, or Business Ethics (e.g., Garriga and Melé 2004; Matten and Crane 2005; Scherer et al. 2009; Scherer and Palazzo 2008a, 2011; Windsor 2006) that have addressed some of the present challenges of globalization and global public goods problems.

This article acknowledges these challenges and the indications offered by the CSR discourse. We thereby connect to an upcoming research stream under the umbrella term of responsible leadership. Responsible leadership is understood by its proponents as an emerging concept at the overlap of studies in ethics, leadership, and CSR (Ciulla 2005; De Hoogh and Den Hartog 2008; Doh and Stumpf 2005a; Maak 2007; Maak and Pless 2006a; Waldman and Galvin 2008; Waldman and Siegel 2008). The concept tries to answer the question: who is responsible for what and toward whom in an interconnected business world?

Our approach adds to the discussion by drawing upon a conception of leadership responsibility that reconsiders the role of leaders in a globalizing society in the context of Habermas's theory of deliberative democracy (Habermas 1999, 2001b). Building on this normative conception of leadership responsibility, the article suggests a model of responsible leadership that provides the premise for future empirical testing.

We thereby contribute, first, to the conceptualization of an emerging concept of responsible leadership by offering a philosophical foundation and a theoretical background both for the analysis of responsible leadership and the problems of globalization. Second, the article shows how responsible leadership can address the challenges of globalization. It thus adds the individual level of leadership to the discussion on corporate social responsibility. Third, we put responsible leadership in the organizational context by highlighting possible influences of responsible leadership on micro-, meso-, and macro-level organizational outcomes. This shows important interdependencies and contributes to the knowledge of an emerging research field. Further, it offers a way of how to translate a philosophical foundation into a practically relevant theory.

Accordingly, the article first recapitulates the argumentation regarding our understanding of leadership responsibility, depicting deliberative democracy (Bohmann and Rehg 1997; Habermas 1998, 2001b) as our explicitly normative cornerstone with respect to the understanding and integration of present leadership challenges. We transform these philosophical foundations into a definition that is the starting-point in modeling responsible leadership. Second, we distinguish responsible leadership from prior leadership concepts. Third, we present a model of responsible leadership, pointing to outcomes of responsible leadership conduct across levels of analysis. The outcomes that will be discussed connect to the rise in problems organizations are facing due to the process of globalization. The presented model of responsible leadership thereby connects the micro perspective of leadership with the macro perspective of CSR, corporate legitimacy, and other important future business challenges. The aim is to provide a research agenda for responsible leadership in order to stimulate future efforts in this field and to advance the understanding of responsible leadership and its future empirical testing.

\section{The Process of Globalization and the Concept of Responsible Leadership}

In accordance with Scherer and Palazzo and others, we argue that globalization, understood as an increased integration of value creation transcending national boundaries, impedes the capability of the nation state system to moderate the outcomes of the economical, political, and social systems. As a consequence, this development leads to governance gaps so that the public interest is insufficiently served (Chandler and Mazlish 2005; Kobrin 2008; Scherer et al. 2006, 2009; Scherer and Palazzo 2007; see also, Beck 2000; Habermas 2001c). The regulatory power of democratic rule of law states is territorially bound, and due to non-intervention in internal affairs international organizations cannot intervene in the public policy of sovereign nation states. As a result, many externalities and global public goods problems, such as protecting human rights, enforcing labor standards, saving the natural environment, or fighting corruption, remain unaddressed (Kaul et al. 
2003). In order to fill the apparent gaps in global governance, many corporations and their leaders voluntarily engage in self-regulation and the production of global public goods (see, e.g., Young 2006). This is a widespread phenomenon, as can be seen in the growing membership of companies in the UN Global Compact, or booming CSR initiatives like the Global Reporting Initiative, the Forest Stewardship Council, or the Social Accounting 8000.

This political engagement, as well as prominent cases of misconduct or negligence by leaders that have affected all stakeholders alike (one might think of cases like Enron or Siemens), have put corporate leaders in the spotlight of public interest (e.g., Kellerman 2004; Lipman-Blumen 2005). It seems that the negative side effects of globalization and the increasing number of corporate scandals lead to an erosion of corporate legitimacy (Palazzo and Scherer 2006), a loss of public trust in leaders and corporations, and to a degradation of social capital.

The globalization of business has far-reaching implications for the constitutional elements of leadership, which include the persons involved, their interaction and the exerted influence as well as their common goal (Patzer 2009; see also exemplary, Bennis 2007; Drath et al. 2008; Yukl 2006). Leaders (and followers alike) are increasingly confronted with heterogeneous cultural contexts, devoid of shared moral orientations or legal frameworks. As moral or ethical conflicts arise in the process of economic activities, business leaders are left without any orientation in regard to morally adequate action. In this situation, the idea of value maximization often becomes the sole surrogate for moral principles. This problem is aggravated by the need to transcend the traditional, internally bound focus of leadership theory (Maak 2007; Maak and Pless 2006b). As leaders increasingly interact with external stakeholders, the notion of influence as based on hierarchical power has to be reconsidered. It needs to be explained what form legitimate influence takes in this context. Finally, CSR has become a strategic impetus on the organizational agenda representing the companies' struggles to maintain legitimacy as a vital resource of business conduct (Palazzo and Scherer 2006; Suchman 1995). Hence, corporate leaders have to mediate social and financial goals without divulging the one or the other in the process of maintaining corporate legitimacy, building trust, and producing social capital.

In order to address these challenges, research emphasizes a stakeholder-perspective of leadership (Waldman and Galvin 2008; Waldman and Siegel 2008), understanding responsible leadership as a "value-based and through ethical principles driven relationship between leaders and stakeholders" (Pless 2007, p. 438). We connect to this research stream (Maak 2007; Maak and Pless 2006a; Pless 2007) and extend it by offering a philosophical basis for the ethical principles that are called for.
We propose an understanding of responsible leadership in the sense of deliberative processes. ${ }^{1}$ Our procedural conception of leadership ethics is based upon Habermas's thoughts on deliberative democracy (e.g., Habermas 1998, 1999, 2001b) that refer to the idea of legitimate lawmaking issuing from public deliberation, and that rest on the philosophical foundation of discourse ethics (Habermas 1993, 1996). It represents an ideal of political autonomy based on the practical reasoning of citizens. The systemic means of coordination (money and power) are supplemented with solidarity as the premises of societal integration and coordination (Habermas 1999).

Within this societal deliberation process, business leaders as exponents of powerful and resource-commanding organizations become central actors, who can secure the quality and (moral) legitimacy of decisions through proactive engagement in the process of societal selfdetermination and the inclusion and mobilization of stakeholders. This idea of business leaders involved in the deliberative democratic processes as the premise of an understanding of responsible leadership provides normative orientation as well as a pragmatic approach to the problems of globally engaged leaders. It does the former through an understanding of practical reason, anchored in the conditions of communicative exchange that approaches culturally alien contexts via an open and reciprocal learning process in which conflicting interests are evaluated (and settled) through rational discourse (Habermas 1993, 2001a; Steinmann and Scherer 1998; Wohlrapp 1998). Such a politically enlarged concept of leadership implies, for the latter, the inclusion of all affected stakeholders in the leadership process in a fair and balanced manner (Waldman and Galvin 2008, pp. 330ff).

For leaders, this means that they should think of the consequences of their conduct for all constituencies that could be affected, that they recognize the legitimate claims of the affected stakeholders, and that they use their influence to initiate active stakeholder dialogues where the involved parties can come to balanced and fair decisions. The inclusion of the (relevant) stakeholders supports a legitimate process, while the weighing and balancing of the legitimate claims leads to a fair outcome. Responsible leaders thereby foster the public exchange of opinions and try to establish institutional modes of communication with stakeholders and the public.

With regard to this, responsible leadership as deliberation and discursive conflict resolution forwards a

\footnotetext{
1 A more thorough discussion on the differences between the approach of Maak and Pless and the conception forwarded by Patzer and colleagues is presented elsewhere (Patzer and Scherer 2010).
} 
pragmatic approach to the daily practice of leadership that centers on a communicative engagement with its stakeholders. In the context of this article, we therefore understand responsible leadership as the awareness and consideration of the consequences of one's actions for all stakeholders, as well as the exertion of influence by enabling the involvement of the affected stakeholders and by engaging in an active stakeholder dialogue. Therein responsible leaders strive to weigh and balance the interests of the forwarded claims. Additionally, responsible leaders foster the public exchange of opinions and engage in public will formation (for a similar definition, see Voegtlin 2011).

Leading responsibly, according to this understanding, means for leaders to open up to a broader target group (the stakeholders) with the goal of securing the legitimacy of the organization in a given society and establishing and maintaining mutually beneficial stakeholder relations. The definition comprises the steps of discursive conflict resolution (Habermas 1993, 1996). Leaders are thereby seen as the exposed persons in an organization who should be able to recognize (moral) problems in their decision-making processes (by being aware of and considering the consequences of one's actions for all stakeholders). They use their influence to provide the arenas for discursive conflict resolution (by enabling the involvement of the affected stakeholders) and invite the affected stakeholder-groups to join the discourse (by engaging in an active stakeholder dialogue). During the discursive decision process, the task of the responsible leader is to try to achieve a consensus among the participants (by weighing the arguments and balancing the interests of the stakeholder claims). This allows for leaders to influence through cooperation and to aim for consensual solutions, as they interact not through a supervisor-subordinate relationship but eventually with equally powerful or resource commanding entities. Responsible leaders, thus, represent the position and the interest of their organization by joining the discourse with arguments that emphasize their point of view.

This definition represents an ideal of responsible leadership that can encounter restrictions in the organizational day-to-day business (see, e.g., Stansbury 2009). We therefore assume that the conceptualization of responsible leadership represents a continuum, ranging from the non-responsible leader to the ideal responsible leader. The end of the continuum, representing the nonresponsible leader, could be characterized as self-interested, egoistic leadership behavior acting solely on an instrumental rationale. The other end, representing the fully responsible leader, would be based on discourse ethics and deliberation as proposed in our political conception of responsible leadership.

\section{Responsible Leadership in Relation to Prevalent Leadership Conceptualizations}

In studying the literature, one will find that aspects of an enhanced responsibility of leaders that go beyond the narrow scope of profit earning are rare (Brown and Trevino 2006; Ciulla 1995; Doh and Stumpf 2005b; Maak and Pless 2006c), despite the early recognition of an enlarged leadership role in Barnard's work (Barnard 1960). In this part, we discuss our approach in relation to prior leadership conceptualizations. As the field of leadership is very broad and fragmented, we cannot discuss all leadership concepts in relation to our proposed concept of responsible leadership in this article. Rather, we try to highlight the differences of the approach that set it apart from most other leadership concepts. These differences appear most prominently in the limitations of current concepts in addressing the problems of globalization.

First, leadership remains predominantly focused on the influence process between leader and employees (see also the common concepts in leadership textbooks, Bass 1990; Rost 1991; Yukl 2006). It does not take into account stakeholder interactions, which become important for securing the legitimacy of an organization. Second, the new approaches to leadership in relation to ethics (e.g., ethical leadership; Brown et al. 2005) remain mostly descriptive in their approach to assessing leadership ethics. Yet, by only describing prevailing moral norms, they do not allow for a critical justification of what is ethically correct. This leads to common sense being the only actual benchmark for what is ethically right (Ciulla 1998). These theories cannot provide ethical orientation for leaders or offer normative advice. Thus, there is still a need for a philosophical foundation of responsible leadership that provides an orientation of how to deal with the conflicting norms of a heterogeneous stakeholder society. This leads to the third point, the tension between ethics and effectiveness. It is often implicitly assumed that a good leader is ethical and effective (Ciulla 1995). The "usual answer [of what a competent leader is,] is a leader who knows how to get results, make profits, etc." (Ciulla 2005, p. 333). But does this mean that he or she is acting responsibly? This question is not fully addressed in leadership research.

Thus, the points where our concept of responsible leadership differs from prior leadership conceptualizations are that, first, responsible leadership is based on an explicit normative framework of discourse ethics and deliberative democracy that goes beyond ethical concepts based on values or deontological monologism that have been susceptible to critique (Habermas 1996; for a similar critique on concepts of CSR, see Scherer and Palazzo 2007); second, responsible leadership is conceptualized as a process model of leadership that is not explicitly related to ethical 
characteristics of the leader (like most of the other leadership theories concerned with ethics), as these characteristics (e.g., good virtues) pose problems with regard to their intercultural justification. Rather, these ethical characteristics are conceptualized as antecedents of responsible leadership conduct (see Voegtlin et al., 2010); third, responsible leadership transcends the internal view of leadership as leader-follower interaction to a view of leadership as leader-stakeholder interaction, which seems to be an important necessity for leadership in a globalized world (see Liden et al. 2008; Maak 2007; Maak and Pless 2006c; Schneider 2002); finally, responsible leadership does not conceptualize leader effectiveness in the sense of financial performance as the main driver of leadership behavior, but, rather, through the effectiveness in establishing consensual solutions that are accepted as legitimate by all affected parties (for a discussion about what is "good" leadership, see, e.g., Ciulla 1995). This is at the heart of the responsibility toward stakeholders and to a certain extent it implies mediating social and economic goals.

\section{A Research Agenda of Responsible Leadership}

The understanding of responsible leadership as presented above offers the possibility to derive a model relating responsible leadership to important outcomes. In this section, we will deduce formal propositions of causal relationships between responsible leadership behavior and important organizational variables in order to advance future research (this approach has similarly been applied for the advancement of other leadership conceptualizations, see, e.g., ethical leadership, Brown and Trevino 2006 or authentic leadership, Avolio et al. 2004a). We propose a model of responsible leadership (see Fig. 1) which highlights important influences of responsible leadership on organizational outcomes across levels of analysis.

For each of the relationships anticipated in Fig. 1, we theoretically derive formal propositions in order to advance future research in the field of responsible leadership. These relationships highlight potential causal effects in relation to responsible leadership that are designed for further empirical investigation. This is not meant to be an exhaustive list of all the possible influences being affected by responsible leadership. It rather presents proposals that advance the conceptualization of the political concept of responsible leadership.

The focus was laid especially on future business challenges caused by an ongoing globalization process, which we think can be best addressed by responsible leadership conduct. The globalization with its consequences of loss of shared moral orientation, widening governance gaps and a growing public awareness of critical company conduct, puts business firms in an ever greater need to build and secure their (moral) legitimacy, to maintain trustful relations with stakeholders and to leverage the social capital inherent in these relations.

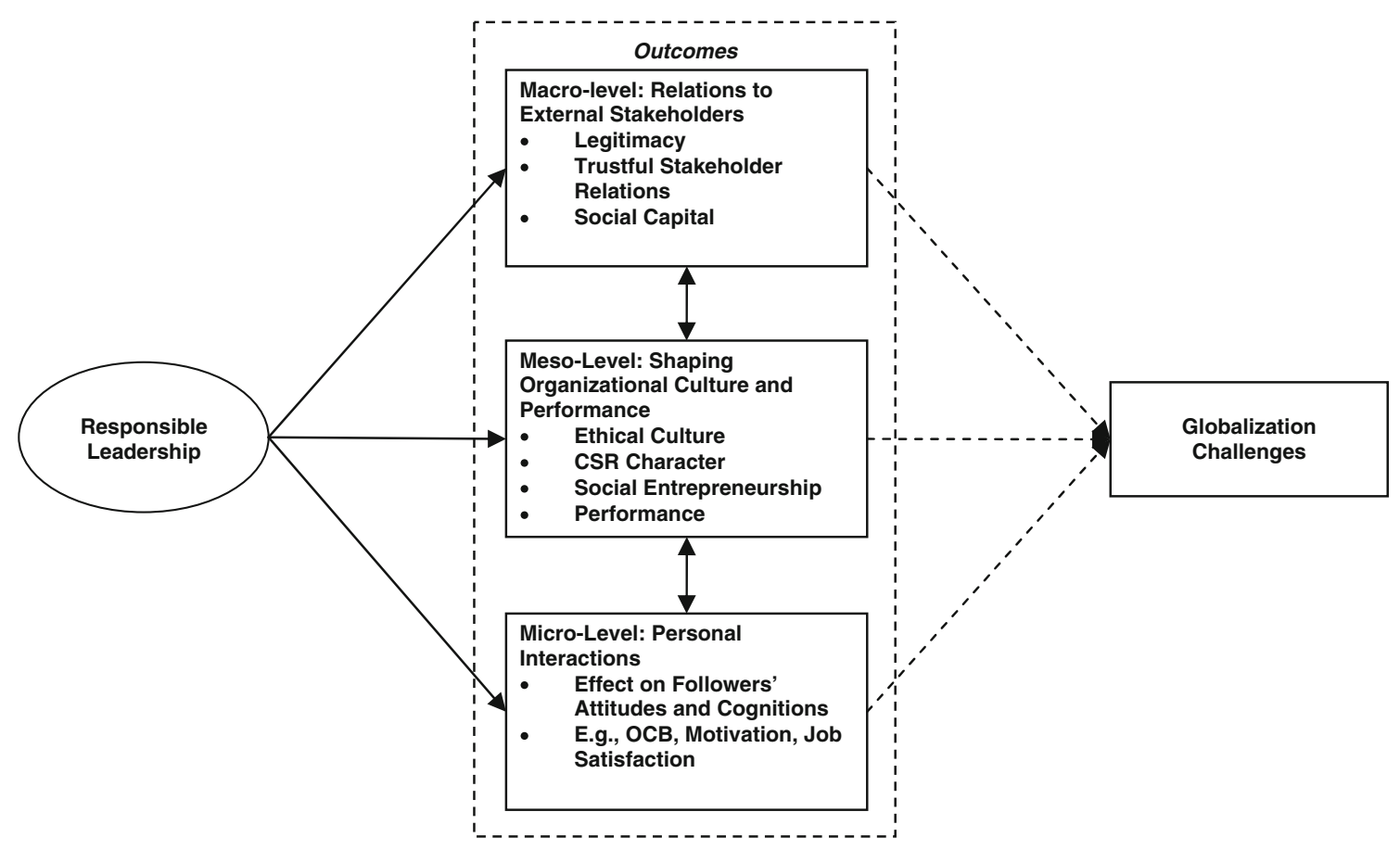

Fig. 1 Outcomes of responsible leadership across levels of analysis 
On the one hand, leaders will have to be role models in terms of good corporate social responsibility practices, thereby trying to foster an ethical culture, as well as emphasizing the need for $C S R$ and providing employees with sense and meaning of the socially responsible activities of their organization. On the other hand, the increasing global competition forces companies to enhance their performance, to innovate faster, and to wage new (social) entrepreneurial ventures.

A further important aspect of business leadership in a work environment with a growing culturally heterogeneous workforce and increased economic pressure is to motivate and satisfy the employees by encouraging them at the same time to engage in citizenship behaviors. These consequences will be discussed in the new model of responsible leadership (see Fig. 1).

\section{How Individual Leadership Can Affect Outcomes Across Levels of Analysis}

Before we discuss the proposed model in detail, we will point to the interaction between leadership agency and (organizational) structures. This implies two questions that need to be addressed: first, in how far is individual leadership action constrained by structures and in how far can agency, in turn, evoke change. Second, how does individual leadership agency affect meso- and macro-level structural dispositions. Both questions also warrant further research and discussion in the (responsible) leadership literature.

Addressing these questions will add to the discussion around leadership and CSR, guide the reader through the framework, and offer a starting point for future research that may investigate this duality in more detail. In this regard, there are limitations to the scope of the discussion in this article. The aim is therefore to present an overview and, at the same time, to encourage other researchers to carry this further.

The macro-level as a point of reference encompasses the interaction of organizations with the broader (global) society, the meso-level is regarded here as the level-ofanalysis of internal organizational structures and practices, and the micro-level is understood as the level of personal interaction of individual agents.

On the meso-level organizational structures can be viewed as historically evolved and socially embedded practices that are enacted through organizational routines, actions, and discourses across all organizational levels (Giddens 1984; Whittington 2010). A similar definition can be applied to institutions on the macro-level: "[institutions] are historical accreditations of past practices and understandings that set conditions on actions" (Phillips, Lawrence and Hardy 2004, p. 637).
Structures and institutions, on the one hand, constrain individual agency in that they limit the possibility of socially desirable or non-sanctioned actions and, in turn, increase the costs of nonconformity (Giddens 1984; Phillips et al. 2004). On the other hand, individual agency shapes these conditions either by reproducing them or by introducing new ways of doing things, i.e., individuals can foster changes in structural conditions over time, especially by facilitating collective action.

The possibilities for leaders to influence these conditions can be derived from the common understanding of leadership as an influence process to foster such collective action (Yukl 2006). Leaders have enhanced possibilities to promote change, as they, first, can draw on a broader set of organizational resources (including authoritarian power provided by the hierarchical position), second, are often seen as role models employees rely upon or look to when directing their actions, and third, can provide meaning or visions that direct change (see, e.g., Bandura 1986; Bass 1990; Yukl 2006).

In the following description of the responsible leadership model, we will not focus on the constraints imposed by structural conditions, but rather on the possible influence of agency through responsible leadership. We thereby assume that the favorable implications of responsible leadership agency can trigger collective action and, subsequently, affect meso- and macro-level outcomes. This should be applicable for all the relationships discussed in the following.

How Responsible Leadership Can Help to Address the Challenges of Globalization: Discussing the Proposed Model

The research agenda of responsible leadership can be extended to possible outcomes of responsible leadership. Responsible leaders are leaders that exert influence by fostering an active stakeholder dialogue. They estimate consequences of their actions and try to weigh and balance different stakeholder claims, in order to achieve mutual beneficial solutions for all involved parties. Such leadership behavior can have an effect on the quality (and quantity) of stakeholder relations as well as on follower attitudes and other important organizational factors.

In the following, we propose positive effects of responsible leadership on stakeholder relations (in the form of legitimacy, trust and social capital), on the ethical culture of an organization, the perceived CSR-Character, social entrepreneurship and organizational performance, as well as on follower attitudes and cognitions (see Fig. 1). These relationships will be discussed based on the macrolevel of leadership relations with external organizational stakeholders, the meso-level of shaping the internal 
organizational culture and affecting organizational performance, and the micro-level of personal interaction with employees.

\section{Macro-Level Outcomes: Fostering Stakeholder Relations}

The negative side effects of globalization and the increase in corporate scandals lead to an erosion of corporate legitimacy (Palazzo and Scherer 2006). On the one hand, leaders are faced with a loss of public trust. On the other hand, the actions of organizations are being monitored to a greater degree by different stakeholders. Leaders are confronted with the challenges of securing legitimacy, (re-)building trustful stakeholder relations and enhancing their social capital (Maak 2007).

We propose that engaging in responsible leadership will help leaders to address these challenges as such conduct will have a positive effect on the relationships with stakeholders. In the following, we will present hypotheses on how responsible leadership can maintain corporate legitimacy, build trustful relationships with stakeholders, and enhance the social capital inherent in those relations.

Legitimacy The new challenges of globalization for the corporation and subsequently for its leaders will eventually lie in the problem of building up and securing the (moral) legitimacy in a given society (Palazzo and Scherer 2006). The post-national constellation, in which the latitude of control by nations over multinational organizations is eroding, leads to a politicization of organizations and thus to higher demands for building up or maintaining their legitimacy (Palazzo and Scherer 2006; Scherer and Palazzo 2007).

Suchman (1995, p. 574) defines legitimacy as "a generalized perception or assumption that the actions of an entity are desirable, proper, or appropriate within some socially constructed system of norms, values, beliefs, and definitions." The ascribed legitimacy of an organization is important for its long-term survival. It guarantees a license to operate in a given society and is "a precondition for the continuous flow of resources and the sustained support by the organization's constituents" (Palazzo and Scherer 2006, p. 71). Suchman (1995) distinguishes three types of legitimacy: pragmatic, moral, and cognitive legitimacy. Pragmatic legitimacy is ascribed when an organization can satisfy the self-interested expectations of the organization's immediate audiences, i.e., its main stakeholders. Cognitive legitimacy rests on the taken-for-granted assumptions of an organization's role and behavior in a society. And moral legitimacy is based on conscious moral judgments and normative evaluation of the organization's activities.

Palazzo and Scherer (2006) argued that the process of globalization, which is also the starting point for our considerations, puts forward an enhanced emphasis on moral legitimacy, as the pluralization of modern society and its resulting cultural heterogeneity erodes the taken-for granted assumptions (of cognitive legitimacy) and cannot be secured solely by changing (exchange-)coalitions with stakeholders (pragmatic legitimacy).

$\mathrm{We}$, therefore, propose responsible leadership as a precondition for securing the moral legitimacy of an organization. Responsible leadership rests on deliberative practices and discursive conflict resolution. Moral legitimacy is built and maintained through communication and participation in public discourses, justifying organizational actions in an active stakeholder discourse with relevant societal actors (Palazzo and Scherer 2006; Suchman 1995). The incorporation of stakeholders in the decision making process and the acknowledgment of their arguments secures legitimate decisions in terms of a fair access (input legitimacy) and in terms of accepted outcomes (output legitimacy).

Taken together, we hold that responsible leadership produces legitimate decisions and thus helps to secure the legitimacy of the organization. It closes the gap with corporate social responsibility in that it guarantees legitimacy for the organizational actions, which could be regarded as the main goal of an extended social responsibility of organizations (see, e.g., Palazzo and Scherer 2006, p. 73).

Proposition 1 Responsible leadership helps to build and maintain the legitimacy of an organization.

Trustful Stakeholder Relations Trust has received a lot of attention in scholarly research (see McAllister 1995; Rousseau et al. 1998), also in the field of leadership (e.g., Burke et al. 2007; Dirks and Ferrin 2002). Trust, seen as a relational process between individuals (e.g., between leaders and followers), has been defined as "a psychological state [comprised] of the intention to accept vulnerability based upon positive expectations of the intentions or behaviors of another" (Rousseau et al. 1998, p. 395). Dirks and Ferrin have distinguished two qualitatively different perspectives of trust in leadership research, a relation-based perspective and a character-based perspective (Dirks and Ferrin 2002, p. 612). The relation-based perspective emphasizes the social exchange process and relates trust to relationships of mutual obligation that inherit goodwill. In relationships that build trust issues of care and consideration are central. From a character-based perspective, the employees place trust in the leader depending on the leader's positive characteristics like, e.g., integrity, fairness, or ability. ${ }^{2}$

\footnotetext{
2 Trust in leadership studies is conceptualized and measured in the form of a perception of followers, attributing trust to the respective leader, and is not based, e.g., on measuring the quality of the relationship directly (Dirks and Ferrin 2002, p. 612).
} 
We propose that responsible leadership conduct evokes trust among those stakeholders a leader interacts with more frequently (not only his or her direct employees or followers) and helps to build mutually beneficial stakeholder relationships. From this point of view, the relation-based perspective will play a more central role than the characterbased perspective, as we do not align responsible leadership with certain characteristics of the leader (which does not mean that responsible leaders will not have those characteristics that promote trust; it could maybe even be hypothesized that they will be more prone to have them). Trust as a relational construct presupposes positive expectations of the intentions or behaviors of leaders from the side of the stakeholders. Preconditions of trustful stakeholder relationships that have been identified are, e.g., transparency, open communication, inclusion and involvement of the stakeholders in the decision making process, and coming to accepted and traceable outcomes (see Burke et al. 2007, pp. 610ff; Dirks and Ferrin 2002, pp. 612ff).

These preconditions are addressed by responsible leadership conduct. Responsible leaders are more likely to build up such trustful stakeholder relationships when they estimate the (negative) consequences of their decisions, use their influence to engage stakeholders in an active dialogue, and weigh and balance the different interests, thereby coming to accepted and mutually beneficial solutions. Being aware of and considering the consequences of decisions helps leaders to avoid negative consequences and enables them to justify the decisions afterward if held accountable by stakeholders. This can lead to more transparent, traceable, and also acceptable outcomes, which in turn are promoters of trustful relationships (Burke et al. 2007; Dirks and Ferrin 2002).

Further, by engaging in an active dialog responsible leaders establish arenas for open communication and foster the inclusion and involvement of the stakeholders, and by aiming for discursive communication situations they create opportunities for acceptable and traceable solutions for all affected parties. Thus, through their frequent engagement in fair and balanced stakeholder dialogs, responsible leaders are able to establish lasting and trustful relationships. Stakeholders who experience a leader as being responsible will generate positive expectations of the intentions or behaviors of this person. This will increase the trustworthiness of the leader and the trust in the relationship to this leader.

Proposition 2 Responsible leadership has a positive effect on building trustful stakeholder relations.

Stakeholder Social Capital Social capital reflects the goodwill inherent in social relationships and is a resource in social networks that can be used to facilitate collective action (Adler and Kwon 2002, p. 17). Social capital was used in the literature as an umbrella term for resources that can be accumulated through social relations (e.g., trust was equated with social capital) (Adler and Kwon 2002; Fulkerson and Thompson 2008). What distinguishes the notion of social capital from what we referred to as trust in the last section is that it is framed as capital that can be mobilized to facilitate collective action. Social capital is built through social exchange processes that rely on exchanges of favors and gifts, in contrast to exchanges that rely primarily on market or hierarchical modes of interaction (Adler and Kwon 2002). The extent of social capital is dependent on the formal structure of the network ties and the content or quality of those ties.

Maak and Pless conceptualized social capital as an essential part of their responsible leadership model (see, e.g., Maak 2007; Maak and Pless 2006c). Maak argues that responsible leadership conduct, which places an emphasis on stakeholder interaction, contributes to building social capital (Maak 2007). Responsible leadership behavior builds social capital in that it facilitates the establishing of a formal stakeholder network by engaging in frequent stakeholder interaction and an active stakeholder dialog. Additionally, responsible leadership behavior should help to accumulate social capital by positively affecting the quality of the stakeholder network as responsible leaders engage in fair and balanced stakeholder dialogs, aiming for discursive decision situations. This signals to stakeholders that their interests will be taken into account and that those relations with responsible leaders go beyond a pure market orientation (in interaction with external stakeholders) or hierarchical exchange processes (in dealing with employees).

The goodwill inherent in social capital could then, in turn, be mobilized to create innovation and to facilitate entrepreneurship (Chong and Gibbons 1997).

Proposition 3 Responsible leadership behavior enhances the social capital inherent in stakeholder relations.

\section{Meso-Level Outcomes: Affecting the Internal Organizational Environment}

In relation to meso-level outcomes, we propose effects of responsible leadership conduct that may change the shared practices and dispositions of an organization.

In the following, we want to establish a preliminary theoretical link between the individual leadership level and the organizational level of corporate responsibility in that we discuss the influence of responsible leadership on the ethical culture and the perceived importance of CSR of an organization. This is a needed future research direction, as, 
first, globalization increases the relevance of CSR for multinational firms and, second, as the link between individual agency and corporate responsibility is still insufficiently addressed (see, e.g., Crane et al. 2008; Heugens and Scherer 2010; Scherer and Palazzo 2008a).

Further, due to the growing complexity and dynamic of the global business environment of organizations, companies are confronted with the challenge of continuous adaption and innovation, also in the form of social entrepreneurial ventures. With regard to this, we focus in the following on the relation between responsible leadership behavior and social entrepreneurship. Finally, leader effectiveness and the effect of responsible leadership on organizational performance will be addressed.

Ethical Environment The work environment, which we refer to as an organization's culture, plays an important part in shaping and directing people's behavior (Schein 1996; Schneider 1975). In relation to responsible leadership, the prevalent ethical culture and the importance of corporate social responsibility, as perceived by the employees within an organization, are important levers for creating a socially responsible organization.

We will look here at the understanding of an ethical culture as proposed first by Trevino and colleagues (Trevino 1986; Trevino et al. 1998) and later expanded by Kaptein (2008). The research stream that focused on the concept of ethical culture in organizations was brought forward by Trevino et al. (Trevino 1986; Trevino et al. 1998). Ethical culture was conceptualized as being part of the overall culture of an organization. It was later advanced by Trevino and colleagues to encompass "the formal and informal behavioral control systems [...] that can support either ethical or unethical conduct in an organization" (Brown and Trevino 2006, p. 601). ${ }^{3}$ The conception of Trevino and colleagues thereby aims at discovering what is generally perceived as ethics within an organization. The normative implications of the ethical culture conception are not specified.

Responsible leadership can gradually influence the ethical culture over time. By enacting responsible leadership practices such leaders may shape the formal (e.g., through their position power and discretion) as well as the informal (e.g., in terms of role modeling) behavioral control systems that direct the ethical behavior in organizations. By continuously displaying a concern for long-term consequences of decisions, by fostering an active stakeholder dialog, and by practicing inclusive communication that considers the

\footnotetext{
3 The informal and formal (social) control systems encompass to a certain extent what is debated in the CSR literature as compliance and integrity approaches, referring to formal rules and laws as well as to informal values (see critically, Stansbury and Barry 2007; Weaver and Trevino 1999).
}

arguments of others, responsible leaders as role models provide an ethical vision of discursive conflict resolution for others. This in turn may affect the perceived ethical culture in organizations by shaping the collective, shared expectations of what is perceived as right or wrong.

In continuance of this, one could also draw on Kaptein (2008) to illustrate the impact of responsible leadership. More recently, he has refined the construct of ethical culture by forwarding a corporate ethics virtues model which proposes seven virtues that prevent employees from acting unethically and, at the same time, stimulate them to act ethically. Those virtues were derived from qualitative interviews, and Kaptein drew on them to develop an expanded measure of ethical culture. The virtues comprise the virtue of clarity, congruency, feasibility, supportability, transparency, discussability, and sanctionability (Kaptein 2008, pp. 924ff).

These are also virtues that can be positively affected by responsible leadership. If, e.g., responsible leaders demonstrate clear ethical standards (in terms of discourse ethical conflict resolution) (clarity) and if those standards are recognized by the employees as a visible guidance for action (congruency), if employees are given the discretion to act upon them (feasibility), and if the ethical standards are supported and made transparent by leaders, as well as left open to discussion, this should encourage an ethical culture with an emphasis on stakeholder dialog and discourse.

Taken together, we propose that responsible leadership, enacted over time, should be able to influence the ethical culture of an organization. Responsible leadership practices will thereby encourage a culture of discourse and deliberation.

Proposition 4 Responsible leaders can gradually change the ethical culture of an organization over time. Responsible leadership will thereby encourage a culture of discursive conflict resolution and deliberative practices.

Perceived Corporate Social Responsibility Another part of the prevalent culture in an organization that responsible leadership can help to shape is the perceived importance of corporate social responsibility (CSR) within the organizational setting. CSR is often used as an umbrella term for concepts dealing with social issues and has been used in many different ways (Scherer and Palazzo 2007). It was often defined in terms of what organizations do in relation to social responsibility (e.g., doing more than what is expected by the law) (see, e.g., Waddock 2008). Basu and Palazzo (2008) argued that this content-driven understanding is not sufficient when it comes to examining how managers and employees think, discuss, and act in relation to CSR. 
They propose a process model of sensemaking and define "CSR as the process by which managers within an organization think about and discuss relationships with stakeholders as well as their roles in relation to the common good, along with their behavioral disposition with respect to the fulfillment and achievement of these roles and relationships" (Basu and Palazzo 2008, p. 124). According to this understanding, the importance of CSR in an organization can be perceived by members of the organization through sensemaking processes. Basu and Palazzo advance their model of CSR-sensemaking along the dimensions of cognitive, linguistic, and conative dimensions through which people in organizations make sense of CSR-related activities. Those dimensions form the "CSR-character" of an organization.

The process model of sensemaking emphasizes the importance of mental models and frames that affect how the external world (including issues of CSR) is perceived by organizational members. This means that these collective, shared mental frames in an organization shape and direct attention toward what is perceived as important by the people working there.

The influence process, which is regarded as a key aspect of the definition of leadership (Yukl 2006), is connected to the management of meaning (Fairhurst 2009). That is, leadership is also a process of sensegiving that affects the mental models of how the world is perceived by organizational members (Fairhurst 2009).

Responsible leaders as managers of meaning can influence the perceived "CSR-character" of an organization by sensitizing their employees for possible social and environmental consequences of corporate actions, by emphasizing, and also by demonstrating in their actions the importance of stakeholder engagement and involvement.

If responsible leaders can convince their employees that CSR is an important topic in their organization, those employees will more readily engage in active stakeholder dialogs when social and environmental issues are at stake. Additionally, if leaders can provide a sense of purpose for the CSR-activities of their organization, their employees will more readily recognize issues of CSR as part of their daily practice and engage themselves in CSR-related actions.

Therefore, we conclude that responsible leadership can contribute to an enhanced awareness of the CSR-character of a firm.

Proposition 5 Responsible leadership can positively affect the perceived importance of CSR in an organization.

Social Entrepreneurship Responsible leaders will be able to foster social innovation. Innovation can be defined as "the generation, acceptance and implementation of new processes, products, or services for the first time within an organizational setting" (Pierce and Delbecq 1977, p. 29). Innovation is an important driver of organizational change and was related to organizational success and competitive advantages (Gumusluoglu and Ilsev 2009).

We propose that the interrelation between responsible leaders and stakeholders from the social and political environment, e.g., NGOs or social movements, can trigger social innovation. For example, expanding the knowledge base and the (technical) knowledge resources was considered to foster innovation. Responsible leadership behavior helps to expand the knowledge base by fostering an active stakeholder dialog where all participants can contribute their knowledge and expertise to solve problems. The same holds for internal and external communication. Both were related to a positive effect on innovation. ${ }^{4}$ Responsible leaders engage in communications with external stakeholders like government officials or NGOs. This creates opportunities for exchanging information and for bringing up innovative ideas. The dialog with internal stakeholders will in turn facilitate the dispersion of ideas within the organization and create a favorable internal environment for innovation.

Responsible leaders fostering social innovation can be regarded as what an evolving stream in the literature calls social entrepreneurs (Nicholls and Cho 2006). Social entrepreneurship is understood as pursuing ventures that bring together a social mission, an emphasis on innovation and a market orientation (Nicholls and Cho 2006, p. 115). Social entrepreneurs thereby play the role of change agents in the social sector (Bloom 2009, p. 128). The change of the institutional systems that social entrepreneurs can achieve depends on the influence they can exert. We propose that responsible leaders, especially in top level management positions, can advance social entrepreneurial ventures that can achieve considerable changes (De Hoogh and Den Hartog 2008; Ling et al. 2008; Waldman et al. 2006), as responsible leadership addresses the balance between a market orientation and recognizing the interests of stakeholders pursuing a social mission, and as responsible leadership conduct brings with it an enhanced possibility for innovation.

Proposition 6 Responsible leaders are more likely to act as social entrepreneurs than non-responsible leaders.

Organizational Performance An important issue concerning the intersection of leadership and responsibility, or ethics, respectively, is the question of what an effective

\footnotetext{
${ }^{4}$ For further literature on the determinants of innovation, see the meta-analysis of Damanpour (1991). The relationships between the determinants and innovation were based on theoretical reasoning and empirical findings (Damanpour 1991, p. 557).
} 
leader is. It revolves around the issue whether an ethically good leader is always an effective leader and vice versa (Ciulla 1995, 2005). The main goal of responsible leadership as proposed here is to contribute to the fulfillment of organizational performance goals. Responsible leadership connects to the understanding of leadership in general, in that it can be regarded as a "process of facilitating individual and collective efforts to accomplish shared objectives" (Yukl 2006, p. 8).

Yet, to act responsibly additionally implies an ethical qualification, which can be understood as an evaluation of the means to accomplish performance goals in the light of moral norms or ethical considerations. This ethical commitment can lead to situational amendments of performance goals if the social cohabitation in a society is in danger of being breached (Scherer 2003, pp. 427ff). A negative example of not considering an ethical qualification would be the case of BP and the 2010 oil spill in the Gulf of Mexico. Previous insights suggest that the managers involved chose the cheaper solution for drilling, taking into account higher risks for the people working on the oil platform, the surrounding environment and those people living on the nearby shores. Their decisions were driven by financial performance pressure from the company (Oil Spill Commission 2011; The New York Times 2010a, b).

An ethical qualification is implicitly built into the definition of responsible leadership, as responsible leaders evaluate their decisions and actions according to the possible consequences and engage in an active dialog to find solutions that can be accepted by the affected parties. Thus, responsible leaders contribute to financial performance under the caveat of only implementing means that are morally legitimate to reach their goals.

Apart from the direct link of responsible leadership and effectiveness, we assume additional indirect positive effects of responsible leadership on the performance of an organization. Mediated by the other outcome variables in Fig. 1, responsible leadership could have a positive effect on social and financial performance of the organization. Responsible leadership was hypothesized to build up trustful relationships and social capital, to foster social innovation and will in the next section be proposed to positively affect followers' attitudes and cognitions. Trust was shown to have a positive effect on performance (Burke et al. 2007; Dirks and Ferrin 2002). The accumulated social capital in stakeholder relations built up by responsible leaders can be used to facilitate collective action (Adler and Kwon 2002), with the aim of enhancing either the financial or social performance of an organization. Social innovation can be hypothesized to enhance the social performance of an organization. Finally, follower attitudes like job satisfaction, motivation, or commitment have been identified as performance drivers (Locke and Latham 2004; Mathieu and Zajac 1990). Thus, taken together, it could be hypothesized that responsible leadership has an effect on the financial and social performance of an organization.

Proposition 7 Responsible leadership contributes directly and indirectly to the performance of an organization under the caveat of ethical or moral means.

\section{Micro-Level Outcomes: Effects on Followers' Attitudes and Cognitions}

Apart from the proposed outcomes, responsible leaders will also have a direct and considerable effect on their immediate followers. To satisfy and motivate employees is still a key challenge of leadership and this aspect should therefore not be neglected in the discussion on responsible leadership.

Leaders in organizations occupy an exposed position and as such are often regarded as role models (Brown et al. 2005; Trevino et al. 2000). Bandura's social learning theory (Bandura 1986) emphasizes the importance of positive role models that help individuals to learn and reinforce what they have learned. Brown et al. (Brown et al. 2005; Brown and Trevino 2006) build their concept of ethical leadership around the reinforcing effect of leaders as positive ethical role models in organizations.

Responsible leaders will have a twofold effect on follower attitudes and cognitions. First, we propose a positive effect of responsible leaders as role models (Bandura 1986; Brown et al. 2005). If followers see that their supervisor incorporates the affected parties in the decision-making process and seeks to make balanced decisions, ideally resolving decision situations in a consensus, they may perceive their leader as an attractive and legitimate role model from whom they can learn the importance of involving others and engaging in discursive practices. An example of how responsible leaders as role models could have a positive effect on follower behavior would be an enhanced organizational citizenship behavior of followers (OCB) (Konovsky and Pugh 1994; Podsakoff et al. 2000). OCB is defined as behavior that shows engagement beyond what is requested from the organization or what would be an enforceable part of the job description or employment contract (Podsakoff et al. 2000, p. 513). Responsible leaders will be positive role models in relation to citizenship behavior, as they think about consequences for stakeholders from the social and political environment and incorporate them in decision situations. This helps to solve the needs of both sides and shows an engagement with societal interest groups, which moves beyond what is requested from the immediate job description. Employees may learn from such appealing leadership behavior. 
Second, there will be a direct effect of responsible leadership on followers, since engaging in an active stakeholder dialog means that responsible leaders also incorporate the immediate followers in far reaching decision-making processes if those decisions would affect them. Participative practices and involving followers in the decision making process was shown to enhance work related attitudes (e.g., empowerment, see Spreitzer 1996). If employees feel that they can actively contribute to decision situations, and if they feel they are regarded as important by their supervisor, this may be hypothesized to affect their attitude toward satisfaction with their job (Spector 1997), their motivation (Locke and Latham 2004), or their commitment to the organization they are working for (Mathieu and Zajac 1990).

Proposition 8 Responsible leadership will have a positive effect on followers' attitudes and cognitions (e.g., job satisfaction, motivation, commitment or organizational citizenship behavior).

\section{Conclusion}

This article has advanced a model of responsible leadership that embeds the leader's responsibility in the process of globalization and the societal efforts of self-regulation in the light of regulative deficits of the nation state and the new quality of global problems. As leadership is increasingly confronted with problems of cultural heterogeneity, moral dilemmas, and ethical conflicts, our understanding of responsible leadership places deliberative and discursive practices at the heart of leadership, thereby aiming for a legitimate and peaceful mode of conflict resolution.

In pragmatic terms, this means that responsible leaders should think about the consequences of decisions for all affected parties and engage in an active stakeholder dialog, weighing and balancing the differing interests. Based on this approach, we discussed positive outcomes of responsible leadership in order to advance the understanding of responsible leadership and its consequences. We addressed the outcome variables along various levels of analysis and focused especially on future business challenges that companies will face due to the globalization process. We proposed responsible leadership as a lever to handle these globalization challenges by highlighting how responsible leadership conduct could positively affect them.

Responsible leadership is distinct from extant leadership approaches, such as, e.g., transformational leadership, ethical leadership, or authentic leadership, as it draws on the theory of discourse ethics and deliberative democracy, conceptualizes leadership as leader-stakeholder interaction, implies an ethical qualification, and proposes consensual solutions as an effectiveness criterion. Subsequently, we suggest that responsible leadership as active stakeholder engagement and discursive conflict resolution should be better able to address the challenges of globalization than existing leadership conceptions. Our model tries to show this theoretically by relating the distinct aspects of responsible leadership to these challenges.

We thus contributed to the literature, first, by advancing the concept of responsible leadership (Maak 2007; Maak and Pless 2008; Waldman and Galvin 2008), and second, by providing a new model that presents a research agenda for the field. The model allows a highlighting of positive effects of responsible leadership and offers a way of how to translate a philosophical foundation into a practically relevant concept.

Finally, we will highlight directions for future research that directly connect to the model of responsible leadership. The first direction would be to empirically test those propositions set up in the article. Therefore, responsible leadership would have to be operationalized. Thoughts could be given on the advancement of an empirical measure of responsible leadership (Voegtlin 2011). In addition to a quantitative research agenda, qualitative approaches could offer further insights for the field in that such research may help to understand how people in organizations make sense of the proposed responsible leadership practices. A fruitful direction would be, for example, to analyze stakeholder dialogs or discursive practices around leadership (Fairhurst 2009; Phillips et al. 2004).

Further, we acknowledge that the presented model of responsible leadership is not final and does not encompass all possible factors that are affected by responsible leadership. Future research could advance the concept by offering additional factors that relate to responsible leadership, such as focusing on drivers of responsible leadership or opportunities for training and development. Additionally, there still needs to be addressed the limitations of the ideal of responsible leadership in daily business, e.g., by discussing the problems of stakeholder dialogs, the costs of establishing consensual solution, or the limits of engaging in public will formation (Stansbury 2009).

Therefore, we suggest expanding the model to a contingency model of responsible leadership. Such a model can be helpful to show the contingencies that foster or allow for responsible leadership behavior in an organizational setting. These contingencies comprise antecedents or moderating influences of responsible leadership (Voegtlin et al. 2010).

In terms of antecedents, it can be distinguished between the structural conditions of hierarchical organizations that constrain or enable leadership and the personal predispositions of the individual. The structural characteristics of 
organizations can impose constraints on the alternatives for action (i.e., the way how people in organizations conduct and experience their work and act in their respective work environment). For example, a centralized and bureaucratic organization and highly specialized tasks with low autonomy and decision responsibility do not offer many possibilities for responsible decisions and active involvement of internal and external stakeholders. On the other hand, job characteristics can offer possibilities for high involvement and active engagement (with one's work). A broader scope of job responsibility, challenging tasks, and participation in important decisions may also encourage leaders further down the hierarchical line to engage in responsible leadership and may support the realization of the positive outcomes mentioned in our model. To examine this more closely could be a fruitful future research direction.

Individual characteristics that may be relevant in fostering responsible leadership behavior are, e.g., moral predispositions. Herein we would subsume personal characteristics and cognitive abilities that encourage moral decision-making. There is a great deal of research that has dealt with morality or ethical questions in the business sphere, addressing the numerous steps in coming to an ethical or moral decision from a psychological or cognitive perspective (see, e.g., Kohlberg 1984; Reynolds and Ceranic 2007; Trevino et al. 2006). If leaders are cognizant of these steps of moral decision-making, if they can reason on a high moral development level (Kohlberg 1984; Rest 1986) and have a strong moral identity (Aquino and Reed 2002; Reynolds and Ceranic 2007), they will be more capable of acting responsibly as understood in our conception of responsible leadership.

Finally, moderating influences on responsible leadership, we would suggest to investigate are, e.g., the hierarchical position of the leader and the department he or she is working in. Both should make a difference in terms of the scope and possibilities of responsible leadership conduct. The hierarchical position of leaders has an impact in terms of the range of the leaders' authority and their access to resources, the frequency of their interactions with stakeholders, the kind of stakeholder engagement, or the scope of their decisions. The department that leaders are working in can restrict or enable responsible leadership conduct by the mere fact that leaders in some departments will have less frequent stakeholder interaction than others. An example would be a supervisor working in a highly specialized and formalized production facility department compared to a leader working in a CSR department.

Taken together, there should be many possibilities to advance the research agenda of responsible leadership theoretically and empirically, possibilities that could offer relevant insights for researchers and practitioners.

\section{References}

Adler, P. S., \& Kwon, S. W. (2002). Social capital: Prospect for a new concept. Academy of Management Review, 27(1), 17-40.

Aquino, K., \& Reed, A. (2002). The self-importance of moral identity. Journal of Personality \& Social Psychology, 83(6), 1423-1440.

Avolio, B. J., \& Gardner, W. L. (2005). Authentic leadership development: Getting to the root of positive forms of leadership. Leadership Quarterly, 16(3), 315-338.

Avolio, B. J., Gardner, W. L., Walumbwa, F. O., Luthans, F., \& May, D. R. (2004a). Unlocking the mask: A look at the process by which authentic leaders impact follower attitudes and behaviors. Leadership Quarterly, 15(6), 801-823.

Avolio, B. J., Luthans, F., \& Walumbwa, F. O. (2004b). Authentic leadership: Theory building for veritable sustained performance. Working Paper, Gallup Leadership Institute, University of Nebraska-Lincoln.

Bandura, A. (1986). Social foundations of thought and action. Engelwood Cliffs, NJ: Prentice-Hall.

Barnard, C. I. (1960). The functions of the executive. Cambridge, MA: Harvard University Press.

Bass, B. M. (1990). Bass and Stogdill's handbook of leadership: Theory, research, and managerial applications (3rd ed.). New York: Free Press.

Bass, B. M., \& Steidlmeier, P. (1999). Ethics, character, and authentic transformational leadership behavior. Leadership Quarterly, 10(2), 181-217.

Basu, K., \& Palazzo, G. (2008). Corporate social responsibility: A process model of sensemaking. Academy of Management Review, 33(1), 122-136.

Beck, U. (2000). What is globalization?. Cambridge, MA: Polity Press.

Bennis, W. (2007). The challenges of leadership in the modern world. American Psychologist, 62, 2-5.

Bies, R. J., Bartunek, J. M., Fort, T. L., \& Zald, M. N. (2007). Corporations as social change agents: Individual, interpersonal, institutional, and environmental dynamics. Academy of Management Review, 32(3), 788-793.

Bloom, P. N. (2009). Overcoming consumption constraints through social entrepreneurship. Journal of Public Policy \& Marketing, 28(1), 128-134.

Bohmann, J., \& Rehg, W. (1997). Deliberative democracy: Essays on reason and politics. Cambridge, MA: MIT Press.

Brown, M. E. (2007). Misconceptions of ethical leadership: How to avoid potential pitfalls. Organizational Dynamics, 36(2), 140155.

Brown, M. E., \& Trevino, L. K. (2006). Ethical leadership: A review and future directions. Leadership Quarterly, 17(6), 595-616.

Brown, M. E., Trevino, L. K., \& Harrison, D. A. (2005). Ethical leadership: A social learning perspective for construct development and testing. Organizational Behavior and Human Decision Processes, 97(2), 117-134.

Burke, C. S., Sims, D. E., Lazzara, E. H., \& Salas, E. (2007). Trust in leadership: A multi-level review and integration. Leadership Quarterly, 18(6), 606-632.

Burns, J. M. (1978). Leadership. New York: Harper Torchbooks.

Chandler, A. D., \& Mazlish, B. (2005). Leviathans: Multinational corporations and the new global history. Cambridge, MA: Cambridge University Press.

Chong, L., \& Gibbons, P. (1997). Corporate entrepreneurship: The roles of ideology and social capital. Group \& Organization Management, 22, 10-30.

Ciulla, J. B. (1995). Leadership ethics: Mapping the territory. Business Ethics Quarterly, 5(1), 5-28. 
Ciulla, J. B. (1998). Ethics, the heart of leadership. Westport, CT: Quorum.

Ciulla, J. B. (2005). The state of leadership ethics and the work that lies before us. Business Ethics: A European Review, 14(4), 323-335.

Crane, A., McWilliams, A., Matten, D., Moon, J., \& Siegel, D. S. (2008). The oxford handbook of corporate social responsibility. Oxford, NY: Oxford University Press.

Damanpour, F. (1991). Organizational innovation: A meta-analysis of effects of determinants and moderators. Academy of Management Journal, 34(3), 555-590.

De Hoogh, A. H. B., \& Den Hartog, D. N. (2008). Ethical and despotic leadership, relationships with leader's social responsibility, top management team effectiveness and subordinates' optimism: A multi-method study. The Leadership Quarterly, 19(3), 297-311.

Dirks, K. T., \& Ferrin, D. L. (2002). Trust in leadership: Metaanalytic findings and implications for research and practice. Journal of Applied Psychology, 87(4), 611-628.

Doh, J. P., \& Stumpf, S. A. (2005a). Handbook on responsible leadership and governance in global business. Cheltenham: Edward Elgar.

Doh, J. P., \& Stumpf, S. A. (2005b). Towards a framework of responsible leadership and governance. In J. P. Doh \& S. A. Stumpf (Eds.), Handbook on responsible leadership and governance in global business (pp. 3-18). Cheltenham: Edward Elgar.

Drath, W. H., McCauley, C. D., Palus, C. J., Van Velsor, E., O'Connor, P. M. G., \& McGuire, J. B. (2008). Direction, alignment, commitment: Toward a more integrative ontology of leadership. The Leadership Quarterly, 19(6), 635-653.

Fairhurst, G. T. (2009). Considering context in discursive leadership research. Human Relations, 62(11), 1607-1633.

Fry, L. W. (2005). Introduction to the leadership quarterly special issue: Toward a paradigm of spiritual leadership. Leadership Quarterly, 16(5), 619-622.

Fulkerson, G. M., \& Thompson, G. H. (2008). The evolution of a contested concept: A meta-analysis of social capital definitions and trends (1988-2006). Sociological Inquiry, 78(4), 536-557.

Gardner, W. L., Avolio, B. J., Luthans, F., May, D. R., \& Walumbwa, F. (2005). "Can you see the real me?" A self-based model of authentic leader and follower development. Leadership Quarterly, 16(3), 343-372.

Garriga, E., \& Melé, D. (2004). Corporate social responsibility theories: Mapping the territory. Journal of Business Ethics, 53, $51-71$.

Giddens, A. (1984). The constitution of society. Oxford: Polity Press. Greenleaf, R. K. (1977). Servant leadership. New York: Paulist Press.

Gumusluoglu, L., \& Ilsev, A. (2009). Transformational leadership and organizational innovation: The roles of internal and external support for innovation. Journal of Product Innovation Management, 26(3), 264-277.

Habermas, J. (1993). Remarks on discourse ethics. In J. Habermas (Ed.), Justification and application (pp. 19-111). Cambridge, MA: MIT Press.

Habermas, J. (1996). Moral consciousness and communicative action. Cambridge, MA: MIT Press.

Habermas, J. (1998). Between facts and norms: Contributions to a discourse theory of law and democracy. Cambridge: Polity Press.

Habermas, J. (1999). Popular sovereignty as procedure. In J. Bohman \& W. Rehg (Eds.), Deliberative democracy: Essays on reason and politics (pp. 35-66). Cambridge, MA: MIT Press.

Habermas, J. (2001a). A genealogical analysis of the cognitive content of morality. In J. Habermas (Ed.), The inclusion of the other: Studies in political theory (pp. 3-46). Cambridge, MA: MIT Press.
Habermas, J. (2001b). The inclusion of the other: Studies in political theory. Cambridge, MA: MIT Press.

Habermas, J. (2001c). The postnational constellation: Political essays. Cambridge: Polity Press.

Heugens, P., \& Scherer, A. G. (2010). When organization theory met business ethics: Towards further symbiosis. Business Ethics Quarterly, 20(4), 643-672.

House, R. J., \& Aditya, R. N. (1997). The social scientific study of leadership: Quo Vadis? Journal of Management, 23(3), 409-473.

Ilies, R., Morgeson, F. P., \& Nahrgang, J. D. (2005). Authentic leadership and eudaemonic well-being: Understanding leaderfollower outcomes. Leadership Quarterly, 16(3), 373-394.

Johnson, C. E. (2009). Meeting the ethical challenges of leadership: Casting light or shadow (3rd ed.). Thousand Oaks, CA: Sage.

Kaptein, M. (2008). Developing and testing a measure for the ethical culture of organizations: The corporate ethical virtues model. Journal of Organizational Behavior, 29, 923-947.

Kaul, I., Conceicao, P., Le Goulven, K., \& Mendoza, R. U. (2003). Providing global public goods-Managing globalization. Oxford: Oxford University Press.

Kellerman, B. (2004). Bad leadership. Harvard, MA: Harvard Business School.

Kobrin, S. J. (2008). Globalization, transnational corporations and the future of global governance. In A. G. Scherer \& G. Palazzo (Eds.), Handbook of research on global corporate citizenship (pp. 249-272). Cheltenham: Edward Elgar.

Kohlberg, L. (1984). The psychology of moral development: The nature and validity of moral stages. New York: Harper \& Row.

Konovsky, M. A., \& Pugh, S. D. (1994). Citizenship behavior and social exchange. Academy of Management Journal, 37(3), $656-669$.

Liden, R. C., Wayne, S. J., Zhao, H., \& Henderson, D. (2008). Servant leadership: Development of a multidimensional measure and multi-level assessment. Leadership Quarterly, 19(2), 161-177.

Ling, Y., Simsek, Z., Lubatkin, M. H., \& Veiga, J. F. (2008). Transformational leadership's role in promoting corporate entrepreneurship: Examining the CEO-TMT interface. Academy of Management Journal, 51(3), 557-576.

Lipman-Blumen, J. (2005). The allure of toxic leaders: Why we follow destructive bosses and corrupt politicians-And how we can survive them. Oxford: Oxford University Press.

Locke, E. A., \& Latham, G. P. (2004). What should we do about motivation theory? Six recommendations for the twenty-first century. Academy of Management Review, 29(3), 388-403.

Maak, T. (2007). Responsible leadership, stakeholder engagement, and the emergence of social capital. Journal of Business Ethics, 74(4), 329-343.

Maak, T., \& Pless, N. (2006a). Responsible leadership. New York: Routledge.

Maak, T., \& Pless, N. (2006b). Responsible leadership in a stakeholder society: A relational perspective. Journal of Business Ethics, 66(1), 99-115.

Maak, T., \& Pless, N. (2006c). Responsible leadership: A relational approach. In T. Maak \& N. Pless (Eds.), Responsible leadership (pp. 33-53). New York: Routledge.

Maak, T., \& Pless, N. (2008). Responsible leadership in a globalized world: A cosmopolitan perspective. In A. G. Scherer \& G. Palazzo (Eds.), Handbook of research on global corporate citizenship (pp. 669-705). Cheltenham: Edward Elgar.

Mathieu, J. E., \& Zajac, D. M. (1990). A review and meta-analysis of the antecedents, correlates, and consequences of organizational commitment. Psychological Bulletin, 108(2), 171-194.

Matten, D., \& Crane, A. (2005). Corporate citizenship: Toward an extended theoretical conceptualization. Academy of Management Review, 30(1), 166-179. 
McAllister, D. J. (1995). Affect- and cognition-based trust as foundations for interpersonal cooperation in organizations. Academy of Management Journal, 38(1), 24-59.

Nicholls, A., \& Cho, A. H. (2006). Social entrepreneurship: The structuration of a field. In A. Nicholls (Ed.), Social entrepreneurship: New models of sustainable social change (pp. 99-118). Oxford: Oxford University Press.

Oil Spill Commission. (2011). Final report. Accessed January 15, 2011, from https://s3.amazonaws.com/pdf_final/DEEPWATER_ ReporttothePresident_FINAL.pdf.

Osborn, R. N., Hunt, J. G., \& Jauch, L. R. (2002). Toward a contextual theory of leadership. Leadership Quarterly, 13(6), 797-837.

Palazzo, G., \& Scherer, A. G. (2006). Corporate legitimacy as deliberation: A communicative framework. Journal of Business Ethics, 66(1), 71-88.

Palazzo, G., \& Scherer, A. G. (2008). The future of global corporate citizenship: Toward a new theory of the firm as a political actor. In A. G. Scherer \& G. Palazzo (Eds.), Handbook of research on global corporate citizenship (pp. 577-590). Cheltenham: Edward Elgar.

Patzer, M. (2009). Leadership and its responsibility under the condition of globalization [Führung und ihre Verantwortung unter den Bedingungen der Globalisierung. Ein Beitrag zu einer Neufassung vor dem Hintergrund einer republikanischen Theorie der Multinationalen Unternehmung]. Berlin/Hannover: Patzer Verlag.

Patzer, M., \& Scherer, A. G. (2010). Global responsible leadership: Towards a political conception. 26th EGOS Colloquium, Lisbon.

Phillips, N., Lawrence, T. B., \& Hardy, C. (2004). Discourse and institutions. Academy of Management Review, 29(4), 635-652.

Pierce, J. L., \& Delbecq, A. L. (1977). Organization structure, individual attitudes and innovation. Academy of Management Review, 2(1), 27-37.

Pless, N. (2007). Understanding responsible leadership: Role identity and motivational drivers. Journal of Business Ethics, 74(4), 437-456.

Podsakoff, P. M., MacKenzie, S. B., Paine, J. B., \& Bachrach, D. G. (2000). Organizational citizenship behaviors: A critical review of the theoretical and empirical literature and suggestions for future research. Journal of Management, 26(3), 513-563.

Rest, J. R. (1986). Moral development: Advances in research and theory. New York: Preager.

Reynolds, S. J., \& Ceranic, T. L. (2007). The effects of moral judgment and moral identity on moral behavior: An empirical examination of the moral individual. Journal of Applied Psychology, 92(6), 1610-1624.

Rost, J. (1991). Leadership for the twenty-first century. New York: Praeger.

Rousseau, D. M., Sitkin, S. B., Burt, R. S., \& Camerer, C. (1998). Not so different after all: A cross-discipline view of trust. Academy of Management Review, 23(3), 393-404.

Schein, E. H. (1996). Culture: The missing concept in organization studies. Administrative Science Quarterly, 41(2), 229-240.

Scherer, A. G. (2003). The multinational corporation and globalization [Multinationale Unternehmen und Globalisierung: Zur Neuorientierung der Theorie der Multinationalen Unternehmung]. Heidelberg: Physica-Verlag.

Scherer, A. G., \& Palazzo, G. (2007). Toward a political conception of corporate social responsibility: Business and society seen from a Habermasian perspective. Academy of Management Review, 32(4), 1096-1120.

Scherer, A. G., \& Palazzo, G. (Eds.) (2008a). Handbook of research on global corporate citizenship. Cheltenham: Edward Elgar.

Scherer, A. G., \& Palazzo, G. (2008b). Globalization and corporate social responsibility. In A. Crane, A. McWilliams, D. Matten,
J. Moon, \& D. S. Siegel (Eds.), The oxford handbook of corporate social responsibility (pp. 413-431). Oxford: Oxford University Press.

Scherer, A. G., \& Palazzo, G. (2011). The new political role of business in a globalized world: A review of a new perspective on CSR and its implications for the firm, governance, and democracy. Journal of Management Studies, 48(4), 899-931.

Scherer, A. G., Palazzo, G., \& Baumann, D. (2006). Global rules and private actors: Toward a new role of the transnational corporation in global governance. Business Ethics Quarterly, 16(4), 505-532.

Scherer, A. G., Palazzo, G., \& Matten, D. (2009). Globalization as a challenge for business responsibilities. Business Ethics Quarterly, 19(3), 327-347.

Schneider, B. (1975). Organizational climates: An essay. Personnel Psychology, 28(4), 447-479.

Schneider, M. (2002). A stakeholder model of organizational leadership. Organization Science, 13(2), 209-220.

Spector, P. E. (1997). Job satisfaction: Application, assessment, causes, and consequences. Thousand Oaks, CA: Sage.

Spreitzer, G. M. (1996). Social structural characteristics of psychological empowerment. Academy of Management Journal, 39(2), 483-504.

Stansbury, J. (2009). Reasoned moral agreement: Applying discourse ethics within organizations. Business Ethics Quarterly, 19(1), 33-56.

Stansbury, J., \& Barry, B. (2007). Ethics programs and the paradox of control. Business Ethics Quarterly, 17(2), 239-261.

Steinmann, H., \& Scherer, A. G. (1998). Corporate ethics and global business: Philosophical considerations on intercultural management. In B. N. Kumar \& H. Steinmann (Eds.), Ethics in international business (pp. 13-46). Berlin: Walter de Gruyter.

Suchman, M. C. (1995). Managing legitimacy: Strategic and institutional approaches. Academy of Management Review, 20(3), 571-610.

The New York Times. (2010a). BP used riskier method to seal well before blast. Accessed July 15, 2010, from http://www.nytimes. com/2010/05/27/us/27rig.html?_r=1.

The New York Times. (2010b). Documents show early worries about safety rig. Accessed July 15, 2010, from http://www.nytimes. com/2010/05/30/us/30rig.html?hp.

Trevino, L. K. (1986). Ethical decision making in organizations: A person-situation interactionist model. Academy of Management Review, 11(3), 601-617.

Trevino, L. K., Brown, M., \& Hartman, L. P. (2003). A qualitative investigation of perceived executive ethical leadership: Perceptions from inside and outside the executive suite. Human Relations, 56(1), 5-37.

Trevino, L. K., Butterfield, K. D., \& McCabe, D. L. (1998). The ethical context in organizations: Influences on employee attitudes and behaviors. Business Ethics Quarterly, 8(3), 447-476.

Trevino, L. K., Hartman, L. P., \& Brown, M. (2000). Moral person and moral manager: How executives develop a reputation for ethical leadership. California Management Review, 42(4), 128-142.

Trevino, L. K., Weaver, G. R., \& Reynolds, S. J. (2006). Behavioral ethics in organizations: A review. Journal of Management, 32(6), 951-990.

Voegtlin, C. (2011). Development of a scale measuring discursive responsible leadership. Journal of Business Ethics, 98(Suppl. 1), forthcoming.

Voegtlin, C., Patzer, M., \& Scherer, A. G. (2010). Responsible leadership in global business: A contingency approach. IOU Working Paper Series No. 106, University of Zurich, Institute of Organization and Administrative Science (IOU).

von Weltzien Hoivik, H. (2002). Moral leadership in action: Building and sustaining moral competence in European organizations. Cheltenham: Edward Elgar. 
Waddock, S. (2008). Corporate responsibility/corporate citizenship: The development of a construct. In A. G. Scherer \& G. Palazzo (Eds.), Handbook of research on global corporate citizenship (pp. 50-73). Cheltenham: Edward Elgar.

Waldman, D. A., \& Galvin, B. M. (2008). Alternative perspectives of responsible leadership. Organizational Dynamics, 37(4), 327341.

Waldman, D. A., \& Siegel, D. (2008). Defining the socially responsible leader. The Leadership Quarterly, 19(1), 117-131.

Waldman, D. A., Siegel, D. S., \& Javidan, M. (2006). Components of CEO transformational leadership and corporate social responsibility. Journal of Management Studies, 43(8), 1703-1725.

Walumbwa, F. O., Avolio, B. J., Gardner, W. L., Wernsing, T. S., \& Peterson, S. J. (2008). Authentic leadership: Development and validation of a theory-based measure. Journal of Management, 34(1), 89-126.

Weaver, G. R., \& Trevino, L. K. (1999). Compliance and values oriented ethics programs: Influences on employees' attitudes and behavior. Business Ethics Quarterly, 9(2), 315-335.
Whittington, R. (2010). Giddens, structuration theory and strategy-aspractice. In D. Golsorkhi, L. Rouleau, D. Seidl, \& E. Vaara (Eds.), Cambridge handbook of strategy as practice (pp. 109126). Cambridge, MA: Cambridge University Press.

Windsor, D. (2006). Corporate social responsibility: Three key approaches. Journal of Management Studies, 43, 93-114.

Wohlrapp, H. (1998). Constructivist anthropology and cultural pluralism: Methodological reflections on cultural integration. In B. N. Kumar \& H. Steinmann (Eds.), Ethics in international management (pp. 47-63). Berlin: Walter de Gruyter.

Young, I. M. (2006). Responsibility and global justice: A social connection model. Social Philosophy and Policy, 23(1), 102130.

Yukl, G. (2006). Leadership in organizations (6th ed.). Upper Saddle River, NJ: Pearson Prentice Hall. 